Article

\title{
Assessing the Learning Effects of Host Communications on the Green Knowledge and Behavior of Festival Attendees-Evidence from Compulsory Garbage Sorting in China
}

\author{
Qi Yan ${ }^{1, *}$, Huawen James Shen ${ }^{2}$ and Yunhong $\mathrm{Hu}^{3}$ \\ 1 Tourism and Social Administration College, Nanjing Xiaozhuang University, Nanjing 211171, China \\ 2 School of International Tourism and Hotel Management, City University of Macau, Macau, China; \\ shenhuawenjames1980@hotmail.com \\ 3 Landscape Architecture College, Nanjing Forestry University, Nanjing 210037, China; hyh@njfu.edu.cn \\ * Correspondence: yorknjen@msn.com
}

check for updates

Citation: Yan, Q.; Shen, H.J.; Hu, Y. Assessing the Learning Effects of Host Communications on the Green Knowledge and Behavior of Festival Attendees-Evidence from Compulsory Garbage Sorting in China. Sustainability 2021, 13, 1839. https://doi.org/10.3390/su13041839

Academic Editor: Susan Clayton

Received: 15 December 2020

Accepted: 3 February 2021

Published: 8 February 2021

Publisher's Note: MDPI stays neutral with regard to jurisdictional claims in published maps and institutional affiliations.

Copyright: (c) 2021 by the authors. Licensee MDPI, Basel, Switzerland. This article is an open access article distributed under the terms and conditions of the Creative Commons Attribution (CC BY) license (https:/ / creativecommons.org/licenses/by/ $4.0 /)$.

\begin{abstract}
Compulsory waste sorting has been in practice in pilot cities in China and is expected to be fully implemented in urban areas of the country by 2025. However, the learning of compulsory waste sorting by non-local festival attendees in a semi-free choice festival context and the roles of the relevant factors require further investigation. In particular, for the non-local attendees, the festival context avails both the opportunity and occasion for effective learning of compulsory waste sorting, a unique research window worth further exploration. Employing a systematic modeling approach to comprehensively investigate the interrelationships among the identified significant factors, this study explores and examines the mechanism of this learning process with a hierarchy of positive relationships between the host communications, learning outcomes and behavioral intentions of the festival attendees concerning compulsory waste sorting. The research subject of this study was a branded forest music festival held in a waste-sorting pilot city in East China, which has long been pivoting to the promotion of environmental-friendly values. The objective measurement of the learning outcomes integrated by this study accentuate the effectiveness of the proposed structural model. Our research findings confirmed all of the hypothesized relationships and established positive learning outcomes for the festival attendees on waste sorting as instructed by the festival hosts. The role of the festival attendees' environmental attitudes in mediating their learning outcomes was corroborated. This study advances the understanding of the experiential learning processes of pro-environment and sustainability knowledge and behavior in festival contexts, areas that require future research attention with growing reflections on and awareness of environmental protection and sustainable development.
\end{abstract}

Keywords: compulsory waste sorting; festival attendee learning; host communications; learning outcomes; environmental attitude

\section{Introduction}

In response to the soaring waste generation as a result of population growth, progressive urbanization and expanding industrialization, in mid-2019 China initiated a revolutionary policy of compulsory waste sorting for its citizens with The Notice for Starting Comprehensively Municipal Solid Waste Sorting in Prefecture-Level Cities and Above Nationwide [1]. The new policy, characterized by a shift from voluntary to compulsory waste sorting, is intended to enhance the efficiency of collecting, sorting, processing and recycling garbage from the source of its production to address the increasingly unsustainable current practices of landfill and incineration that account for over $90 \%$ of waste disposal in the country, which totaled over 210 million tons in 2019 [2]. Following a typical public policy making pattern of centralized coordination, mass mobilization and trial and error correction [3], the policy designated a preliminary batch of 46 pilot municipalities to fully 
implement compulsory garbage sorting by the end of 2022 and set the goal of waste sorting in the entire country by the end of 2025.

By mid-2020, several cities had already launched compulsory waste sorting policies with localized specifications, including the metropolises of Shanghai (since July 2019) and Beijing (since June 2020) [1]. The local policy versions are comprehensive regulations stipulating the major aspects of waste sorting, including: the classification of municipal waste into four categories of recyclable waste, hazardous waste, household food/kitchen waste and residual waste; the set up and operation of sorted waste bins; designated times for the disposal of sorted waste by households; sorted disposal of waste in public places; and penalties and rewards for individuals, companies, institutions and so forth [3].

Effective educational and communications schemes are recognized as crucial in cultivating pro-environmental knowledge and behavior of the public, especially when it comes to issues such as compulsory waste sorting, which requires comprehensive and in-depth understanding, attentive engagement, reinforced skills and normalized compliance [4,5]. Numerous cases have been reported concerning the hardship and struggle experienced by the general public in grasping the gist of waste sorting policies, particularly the parts concerning the accurate execution of the four classifications of waste [6].

The fact that compulsory waste sorting regulations should be seriously learned by members of the public with varying demographic and background features, such as age, residential status, educational level and vocation, further necessitates the significance of devising and implementing public educational programs that can effectively and positively engage the public, orientate public expectations and perceptions, facilitate knowledge generation and transfer and consolidate learning, thereby realizing the expected policy outcomes. Appropriate interpretation and education can duly complement penalty or reward regimens that are found to be less effective in intervening individual pro-environment motivations and actions [7].

The research is still scant on how pro-environment knowledge and behavior can be cultivated in free choice learning contexts. In view of the significance of waste sorting as an integral part of green knowledge and behaviors in contemporary China, this study intends to fill a current research gap by assessing the learning effects of festival host interpretation on waste sorting knowledge and the behavior of non-local attendees for festivals held in locales in China where compulsory waste sorting is in practice. The research subjects of this study are festival attendees who are from places where compulsory waste sorting is not yet in place but have to abide by the compulsory sorting regulations while staying at their destination.

Thus, by utilizing the perspective of experiential learning in festival activities imbued with environment-related themes, this study provides an innovative theoretical contribution to revealing and assessing the learning outcomes of pro-environment knowledge by visitors as a significant social cluster whose annual numbers are typically several times those of the residential population of the destination [8]. On top of that, although it has been established that learning is one of the top motivators driving festival attendance, participation and engagement $[9,10]$, little research has been done on analyzing the unique mechanisms of attendee learning in the semi-free choice settings facilitated by host interpretation.

With the integration of both mindful and non-mindful attendee perceptions, this study helps capture and model such a learning mechanism by identifying and evaluating the main factors affecting attendee perception of the host's interpretation and accounts for how these factors affect the learning outcomes of visitors on compulsory waste sorting. This study also incorporates the endogenous construct of a festival attendee's environmental attitude and examines the mediating effects on the relationship between the attendee perception of the host interpretation and attendee learning outcomes as well as behavioral intentions. Therefore, practical implications can be derived accordingly on how the learning outcomes of festival attendees regarding waste sorting can be retained and accommodated into their original social contexts and personal lives after the festival, to help realize a 
smooth transition for the ultimate application of the compulsory waste sorting policy in the whole country by 2025 .

\section{Literature Review}

\subsection{Waste Sorting at Festivals}

Festivals, as themed series of events with leisure or cultural features, are gaining growing popularity by catering to the cravings for innovative lifestyles and escape in members of modern society [11]. Festivals are becoming avenues for green practices, such as lower environmental impacts on nature, efficient energy and resource usage, the application of innovative green technologies and so forth, with waste sorting being no exception [12]. Waste management has, in fact, become one of the primary issues in festival hosting and management, as the enormous temporal and spatial intensities of festival attendees can impose a strain on the waste handling capacity of the host locale, in some cases rocketing to 10 times the daily average [8]. The commercial vibes of festivals and the underlying consumerism have made them huge generators of waste, with residual waste ranked first, followed by food and kitchen waste and packaging waste.

Food waste source separation has been highlighted as a major area of waste sorting at festivals, especially in terms of the packaging of retailed food and drink, requiring waste production practices at both the canteen facilities and the venue at large [13]. The supply chains of festival goods and facilities should also be effectively communicated with and coordinated in the waste management at the festivals [14]. The importance of effective indicators assessing waste management efficiency and performance is also stressed [15]. The demographic and psychological attributes of festival attendees have also been determined to influence their degree of participation in waste prevention and management measures at a festival. In particular, attendees with family members tended to be more active in participating in waste sorting, thereby indicating group dynamics influence waste sorting, which can be effectively invoked at a festival [16].

In recent years, the idea of green festivals with zero-waste principles has been taken up by festivals around the world, with the strategic objectives of improving the competitiveness of festivals, reducing negative environmental impacts and improving the appreciation of the social implications of such festivals [12]. Festivals have been traditionally associated with concepts of social experimentation and the suspension of cultural norms, realized through the intensive embodied engagement of the attendees with the physical environment and their peers sharing similar social and cultural values [17]. In particular, the shared psychological status of festival attendees can facilitate the popularity of festivals as a site for attendee education regarding more sustainable lifestyles and waste sorting [13]. Therefore, long recognized as cultural laboratories for trying new identities, festivals have been deemed as apt sites for the intervention and promotion of innovative environmental protection initiatives in waste sorting [15].

\subsection{Festivals Recast as Ideal Avenues of Learning for Attendees}

The relationship between learning and festival attendance has been so close that learning is the central component constituting the growing body of serious leisure at festivals, which refers to festival leisure activities actively imbued with experience accumulation and knowledge and skill development [18]. Festival activities that can be categorized as serious leisure with pronounced learning and education themes encompass a wide range of cultural, heritage, ecological and medical areas, with the emerging popularity of education and study-centered festivals as no exception $[9,12]$. Learning and education experiences are not always equated with unpleasurable mental labor, which is mutually exclusive with entertainment and aesthetic experiences that are of a "purer" leisure nature; indeed, learning has been identified as an important dimension of entertainment-themed festivals and events [19]. In this sense, a symbiotic relationship between festival attendance and learning has already been established and consolidated, with the acquirement of learning outcomes at the personal, group and inter-cultural levels availed by festival attendance. 
In the context of festivals, the motivations for and benefits of learning have been long regarded as key pillars underlying the integral festival experience, with the purpose of learning dating back to the earliest forms of festivals and events and spawning the modern era of festival planning and hosting [19]. Learning and education have been elucidated in either explicit or implicit manners in semantic elaborations on the motivations of festival and event attendance, such as the push and pull model and event career framework, with learning and education congenial with such motivations as novelty seeking, social skills cultivation, self-development and self-actualization [20,21]. Particularly, learning is further confirmed as a psychological reward that can offset the potential burden of the attendees' cravings for an escape from reality [15].

\subsection{Visitor's Mindful and Non-Mindful Learning Processes Intervened by Interpretation}

Visitor learning has been classically theorized as composed of free choice physical and mental processes whose formation and consolidation are determined by external cognitive, sensual and emotive stimuli availed and enriched by travel and the endogenous psychological experiences and reflections of the visitor [18]. This conceptualization is in line with the Stimulus-Organism-Response (S-O-R) framework delineating the mechanism of the internalization of external attributes through cognitive, perceptual, physiological, emotive and contemplative activities and accounting for their measurable reactions and outcomes [21].

In contexts where professional interpretation is involved in visitor learning and education, the conceptualizations of mindful and non-mindfulness account for a multitude of factors influencing visitor learning outcomes under such scenarios. Visitor mindfulness is defined as a thoughtful state of mind that is alert and receptive to external stimuli [22]. Stressing a focus on the cognition of new things in the present moment and discarding existing judgments, the concept of mindfulness is deemed to be consistent with travel-embedded learning with the provision of an authentic present context that may be unavailable or undiscovered by others $[19,22]$.

Mindfulness is characterized by positive thought processes of reinforced assimilation, cognitive perception and retroactive association [23]. Mindfulness can be embodied by positive outcomes in the cognitive as well as judgmental and affective realms [20]. Cognitive outcomes cover advanced aptitudes of learning, such as synthetic evaluation, in-depth understanding and the generation of innovative insights; judgmental and affective outcomes involve the attitudes, positive emotions, values and contemplations on temporal and spatial connections and comparisons. Thus, it is easier for mindful visitors, who are more sensitive to context, to cultivate a higher appreciation and report more profound learning outcomes.

Compared with mindfulness, which involves serious thought-provoking and deep learning, non-mindfulness pertains to a more informal and flowing state of the mind, signified by the perception and experience of relatively parsimonious and superficial feelings [21]. Non-mindfulness concerns the entertainment, relaxation and socialization pursuits of the visitor, reflecting the free-choice contexts of travel as a unique learning experience. Although a lower degree of apprehension, appreciation and connections are related to non-mindfulness, it is not antithetical to learning as hedonic values, like fun, enjoyment and excitement, can be aroused and accentuated by non-mindfulness which can encourage a greater level of interest, desire, attention and multi-sensual engagement, all of which help to achieve satisfactory and meaningful learning outcomes [24,25]. Luo, Tsaur and Lo [23] further purported that learning for fun is a distinguishing asset of travel-related learning experiences.

The capability and skills of effective knowledge interpretation and communication that arouse the immersion into, absorption of and connections to such knowledge by visitors have been deemed to be key performance indices of the competence of the host narrators or interpreters $[26,27]$. At the same time, for non-special goal-oriented visitors, the host needs to attend to and moderate their reflective and affective states, which can be dynamic during the event in response to their interactions with the host and the visited 
places, so as to leverage visitor satisfaction and yield the expected learning outcomes [28]. In this regard, the learning experiences of visitors are co-constructed and shaped by both the host interpretations and the manner of engagement with the interpretations by the visitors as determined by their extent of mindfulness in the process. In addition, for group visitors, collective mindfulness with an enhanced mindset, resilience and capability can be formed and consolidated in a group-learning environment, galvanizing their learning outcomes [29].

\subsection{Visitor Environmental Attitude}

A visitor's environmental attitude is defined as the evaluative feelings, concerns, beliefs, stances and value systems held by the visitor regarding the environment [30]. It can be regarded as a consequential outcome of environmental perception, which is located at a higher position of the psychological order. The environmental attitude is also the antecedent that can directly predict and determine the behavioral intentions as well as the actual behavior of an individual concerning the environment, to such an extent that attitude can be viewed as proxy for likely behavior [31].

The hierarchal relationships among these psychological attributes, as well as the fulcrum function performed by attitude, can be accounted for by the theory of planned behavior (TPB) [32]. In TPB, together with the normative beliefs and perceived behavioral control that represent the external social and cultural contexts, attitude links the behavioral beliefs which relate to the opinions and evaluations of the target behavior and the behavioral intentions that can be derived. Thus, the environmental attitude assumes its significance by serving as the crucial bridge spanning what one thinks about and what one will do with the environment.

Environmental attitudes are complex in their structure and can be divided into three closely related and consequential layers of cognitive, affective and conative attitudes, corresponding to the rational, emotional and moral, as well as the explicit and expressed stages, which constitute the inextricable wholeness of one's environmental attitudinal propensities [33,34]. In this regard, environmental attitude is pronounced within social contexts, in the forms of both normative systems as knowledge and information, as well as subjective norms, such as social pressures and cultural expectations.

These social contextualizations have been duly reflected in classic environmental attitude measurement scales, including the New Environmental Paradigm and the New Ecological Paradigm, which incorporate ecological as well as social and political attitudinal aspects [33]. Thus, environmental attitude is often a trade-off between a sense of control with the influences of non-volitional factors regulating rational perception and decision making, which together constitute one's personal efficacy on the environment [35]. In the meantime, the crucial role of environmental education in cultivating environmental attitudes is also recognized [36].

As a value-laden construct with rich judgmental dispositions along a continuum marked by the bipolarities of positivity and negativity, environmental attitude has been empirically proven to be a reliable antecedent for pro-environment responsibilities and behavioral intentions and actions of visitors [32,34]. Underpinned by both individual experiences and group contacts, attitude can be enduring and resistant to change and can be readily transformed into repeat consumption and loyalty behaviors of the tourist [32]. In particular, environmental attitudes have been found to boost positive correlations with people's recycling and green purchase behaviors [37]. Thus, environmental attitudes are considered as an important variable in the current study.

\subsection{Current Research Aims}

A review of the literature indicates that, while there have been research efforts on the issue of festival attendee learning, many of which are environment- and eco-themed, most have been focused on festivals that are oriented at environment- or education-centered tour activities, with few addressing the research issue of this study which is characterized 
by a semi-free choice learning context. The research subjects of this study were attendees participating in a music festival encountering the new phenomenon of compulsory waste sorting at the festival site, with knowledge of the prospect of implementation of compulsory waste sorting in their places of residence in the near future. Thus, the exploration and examination of how their special social normalizations regarding compulsory sorting and relevant behaviors are cultivated during an intensive and intervening travel experience is intended to enrich the understanding of the mechanism of environment-related learning in non-traditional contexts and its lasting impacts concerning an issue with immense practical implications [38-40].

On top of that, due to mostly concentrating on the subjective evaluative stances reported by visitors, previous studies have not investigated visitor learning effects with more objective measurements. There is a salient lack of research and application of tenable theoretical angles on the functions of host interpretation in facilitating and influencing environmental learning outcomes and pro-environmental behaviors of festival attendees with regard to compulsory waste sorting [41,42].

This study intends to fill a current research gap by gleaning insights into how festival attendees' perception of the host interpretation of compulsory waste sorting regulations and practices at the festival site affect their learning outcomes and behavioral intentions regarding compulsory sorting. The mediation effects of the environmental attitude of festival attendees on the relationships between the perception of the host interpretation and learning outcomes are examined.

Figure 1 presents the conceptual framework of this study and the proposed interrelationships among the research variables. Specifically, the antecedent variable formulated is the perception by festival attendees of the host interpretation of compulsory waste sorting at the destination, which is conceptualized from theoretical elaborations on attendee mindfulness and non-mindfulness. The variables of the learning outcomes of festival attendees and their behavioral intentions concerning compulsory waste sorting were constructed as the consequences of the antecedent variable and the mediator of the environmental attitude of the festival attendees.

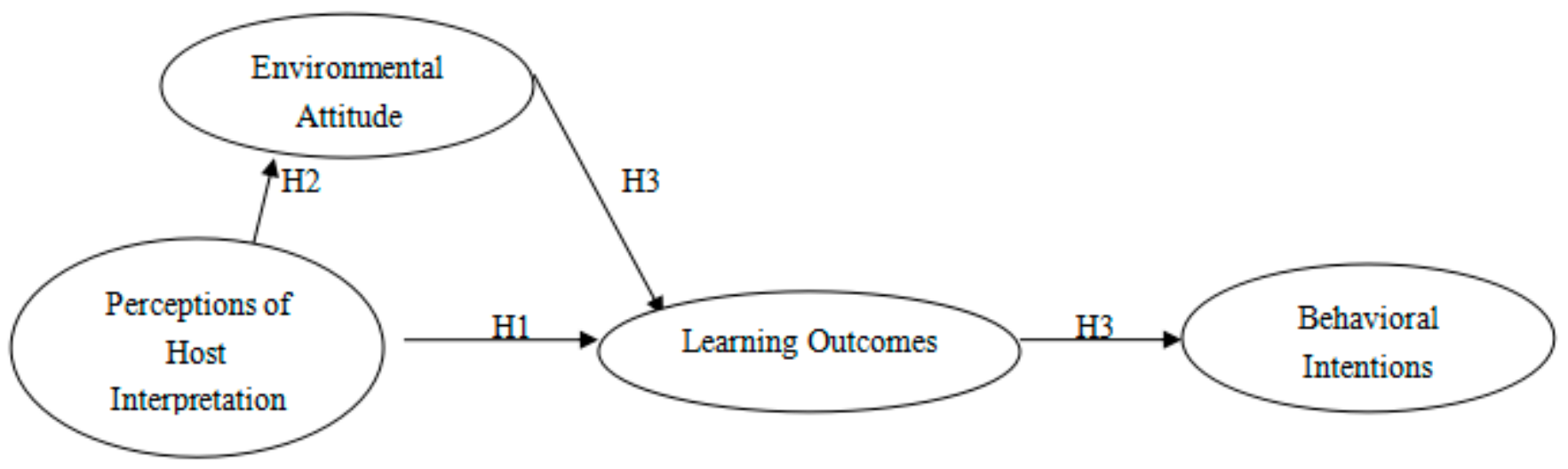

Figure 1. Conceptual framework of the study.

Correspondingly, the following three hypotheses are postulated:

Hypothesis 1 (H1). Perception of the host interpretation has a positive effect on the learning outcomes of festival attendees on compulsory waste sorting.

Hypothesis 2 (H2). The effect of the perception of the host interpretation on the learning outcomes of festival attendees on compulsory waste sorting is mediated by their environmental attitude.

Hypothesis 3 (H3). Learning outcomes of festival attendees on compulsory waste sorting have a positive effect on their behavioral intentions concerning this issue. 


\section{Methodology}

\subsection{Measurement}

This study follows an inductive and triangulation approach in formulating, coalescing and improving the content validity of the respective measurement scales of the examined variables and their hypothesized interrelationships. An in-depth and extensive literature review was first conducted to generate a preliminary cohort of measurement items, with special attention being paid to previous research on visitor learning of environmental issues, environmental learning in festival and event contexts, as well as host-attendee communications and interactions $[17,28,43-45]$. Specifically, relevant regulations and documents on compulsory waste sorting at the festival destination were perused to design the measurement of the learning outcomes of the festival attendees on compulsory waste sorting.

The proposed items were also adjusted to be better tuned to the unique research context of this study regarding compulsory sorting. In the second phase, three senior experts-one from academia, one from the industry with an advanced certificate of festival organization and one government official working at the local environment authoritieswere invited to offer input and refinement on the scales. Following the protocols suggested by Lee and Crompton [46], the revision process placed emphasis on the relevance of the items to the research issue, the extent of the representativeness of the items with regard to the research objectives, social and cultural peculiarities of the research subjects and the appropriateness of the wording of the items.

The triangulation generation process was finalized with a five-dimension measurement 28-item scale of the perception by the festival attendees of the host interpretation of compulsory waste sorting based upon previous theoretical articulations on mindful and non-mindful learning in festival and event contexts, encompassing the variables of knowledge, engagement, interest, the matching degree and group learning atmosphere. The learning outcomes were presented in the form of a quiz of seven multiple choice questions (Table 1). The environmental attitude and behavioral intentions of the festival attendees were evaluated by five and four items, respectively, based upon the literature $[33,35,40]$. Except for the learning outcomes, which were assessed by the accuracy of the respondents' answers to the quiz, all measurement items in this study were evaluated with a 7-point Likert scale $(1=$ strongly disagree to $7=$ strongly agree $)$.

Table 1. Measurement of learning outcomes of festival attendees on compulsory waste sorting at the destination.

\footnotetext{
1. Can compulsory waste sorting lower carbon emissions?

A. Yes B. No C. Maybe D. I do not know

2. Leftover food can be disposed of at the following public locations of the destination EXCEPT:

A. fast food restaurants B. the hotel where I stay C. bins on the street D. convenience stores

3. Dry flowers should be categorized as

A. residual waste (dry garbage) B. household food/kitchen waste (wet garbage)

C. recyclable waste D. hazardous waste

4. If a napkin is stained, it should be categorized as

A. residual waste (dry garbage) B. household food $/$ kitchen waste (wet garbage)

C. recyclable waste $\mathrm{D}$. hazardous waste

5. Which of the following is NOT household food/kitchen waste (wet garbage)?

A. vegetable leaves B. pork bones C. consumed tea leaves D. fruit peels

6. Which of the following is NOT hazardous waste?

A. broken glass B. used bulbs C. expired medical pills D. used batteries

7. The highest penalty for non-compliance with compulsory waste sorting in the province is

A. 50 yuan B. 100 yuan C. 200 yuan D. 300 yuan
}

\subsection{Data Collection}

The data for the study were collected in mid-November 2020 from non-local festival attendees participating in a branded forest music festival held in a waste-sorting pilot city in East China. Held in a local forest park with three acres of forests, hillsides, meadows and 
ponds with stages, campsites and leisure facilities, the three-day-long festival has been in place since 2015 and was successfully branded by local tourism authorities as an attraction for visitation and participation during traditionally low seasons of tourism. The programs of the annual festival, which has already earned national fame and been gravitated toward by a cornucopia of followings each year, encompass outdoor and indoor concerts, music performances and shows from popular bands, singers and artists, as well as nature-based and curated activities, among others.

In particular, sensitivity toward environmental issues has been traditionally embedded into the theme of the festival. The respondents were from other places in China where compulsory waste sorting was not yet in place. Data collection was conducted on the selected attendees led by three festival hosts, who had been briefed and trained on the research purpose and particulars of this study. At the registration of the festival, the attendees were handed an official booklet regarding the compulsory waste sorting regulations at the destination and were informed by the host about the potential consequences for non-compliance. Information and knowledge on compulsory waste sorting was intensively interpreted by the hosts on three major occasions of during the intervals of the concerts, in the lobby of the on-site accommodations and during individual group activities. Assisted by complementary written and e-version materials provided and edited by the researchers, the instructions of the festival host covered aspects such as rationale for waste sorting, classifications of waste, waste sorting policies and penalties and so forth and would respond to any questions raised by the attendees during the instruction process. On other occasions throughout the festival, the host would introduce and explain the compulsory waste sorting when necessary and upon inquiry by the attendees individually.

At the end of the festival, surveys in electronic form were distributed through the platform of the social networking software WeChat to the festival attendees for completion. In view of the nature of the study, the age limit of the respondents was set above 18 years old. Questions raised by the festival attendees during completion were answered by the hosts in a timely fashion and further clarifications and guidance were provided if needed. Attendees who successfully completed and submitted the survey received a small handcrafted souvenir of the festival. Altogether, of the 320 questionnaires returned, 282 were readied for further analysis after an initial screening for missing data and incomplete information.

\subsection{Data Analysis}

The data analysis was conducted using the statistical analytical software SPSS 26.0 and AMOS 21.0 to compare the differences among certain demographic sub-groups of the respondents with regard to the research objectives, to test the tenability of the proposed scales of the variables and to validate the hypothesized interrelationships among them. Confirmatory factor analysis (CFA) was applied to investigate the internal validity as well as the reliability of the proposed scales, together with the analysis of dimensionality as well as convergent and discriminant validity [45]. Finally, structural equation modeling (SEM) was employed to test the fitness and congruity of the hierarchy comprising the hypothesized interrelationships among the variables in the conceptual framework.

\section{Results}

\subsection{Descriptive Statistics}

The demographic details of the respondents are summarized in Table 2. Females accounted for $62 \%$ of the total sample and males were $38 \%$. The distribution of age of the respondents was quite even among the five sub-groups, with the highest ratio reported for those below 35, reflecting the major customer segments of this genre of festival in China. Nearly half of the sample (49\%) were educated to the undergraduate level, followed by high school (30\%). Personal monthly income was also found to be quite evenly distributed among the sample, with 31.2\% earning 3001-5000 RMB monthly. The majority (58\%) of the sampled festival attendees were first time participants in the festival. With regard to their previous knowledge about compulsory waste sorting, most reported little (66\%) 
or some $(29 \%)$ prior knowledge, thereby indicating the function of the tour in offering opportunities for them to experience and learn about compulsory waste sorting, which would be otherwise available.

Table 2. Demographic profile of the respondents.

\begin{tabular}{|c|c|c|c|}
\hline \multicolumn{2}{|c|}{ Variable } & \multirow{3}{*}{$\begin{array}{c}\mathbf{n} \\
108 \\
174\end{array}$} & \multirow{3}{*}{$\begin{array}{c}\mathbf{\%} \\
38.3 \\
61.7\end{array}$} \\
\hline & Male & & \\
\hline Gender & Female & & \\
\hline \multirow{5}{*}{ Age } & $18-24$ & 72 & 25.5 \\
\hline & $25-34$ & 64 & 22.7 \\
\hline & $35-44$ & 58 & 20.6 \\
\hline & $45-54$ & 50 & 17.7 \\
\hline & 55 and above & 38 & 13.5 \\
\hline \multirow{4}{*}{ Education } & Primary school or below & 41 & 14.5 \\
\hline & High school & 85 & 30.1 \\
\hline & Undergraduate & 137 & 48.6 \\
\hline & Postgraduate or above & 19 & 6.8 \\
\hline \multirow{4}{*}{ Personal Monthly Income } & $3000 \mathrm{RMB}$ and under & 72 & 25.5 \\
\hline & 3001-5000 RMB & 88 & 31.2 \\
\hline & 5001-8000 RMB & 75 & 26.6 \\
\hline & More than 8000RMB & 47 & 16.7 \\
\hline \multirow{3}{*}{ Experience of Attendance at the Festival } & First time & 164 & 58.2 \\
\hline & Two to three times & 82 & 29.1 \\
\hline & Four times and above & 36 & 12.7 \\
\hline \multirow{3}{*}{ Previous Knowledge about Waste Sorting } & Little knowledge & 185 & 65.6 \\
\hline & Some knowledge & 81 & 28.7 \\
\hline & Familiar & 16 & 5.7 \\
\hline
\end{tabular}

Particularly with regard to the results of the learning outcomes of the festival attendees on compulsory waste sorting, a satisfactory mean score of 5.27 of the seven quiz questions was yielded and one-way ANOVA analysis revealed that there were no significant differences in this respect among the groups of respondents of different ages $(\mathrm{F}=1.371 ; p=0.322)$, education levels $(\mathrm{F}=1.520 ; p=0.178)$ or prior knowledge about waste sorting $(\mathrm{F}=1.392$; $p=0.287)$. Interviewees with an undergraduate degree secured the highest scores, followed by postgraduate and above and high school level. The similar score results of the learning outcomes among the groups with different extents of prior knowledge about waste sorting demonstrate the considerable learning effects of host interpretation during the festival.

\subsection{Measurement Models: Confirmatory Factor Analysis (CFA)}

Confirmatory factor analysis (CFA) was performed to test the internal validity and reliability of the proposed dimensionality of the perceptions of festival attendees of the host interpretation of compulsory waste sorting. The analytical results are displayed in Tables 2 and 3. A satisfactory level of internal consistency within each of the five postulated dimensions of the perceptions of host interpretation was achieved, with the range of composite measures of reliability from 0.77 to 0.91 . 
Table 3. Measurement model results.

\begin{tabular}{|c|c|c|}
\hline Dimension & Composite Reliability & Standardized Factor Loadings \\
\hline Perception of host interpretation -Knowledge on compulsory waste sorting & 0.86 & \\
\hline Host interpretation is accurate. & & 0.848 \\
\hline Host interpretation is comprehensive. & & 0.905 \\
\hline Host interpretation is clear. & & 0.870 \\
\hline Host interpretation is easy to understand. & & 0.824 \\
\hline Host interpretation is complementary to text materials. & & 0.868 \\
\hline Pace of host interpretation is appropriate. & & 0.889 \\
\hline Perception of host interpretation-Engagement & 0.77 & \\
\hline Host offers on-site demonstration. & & 0.810 \\
\hline Host assists with attendees' participation. & & 0.755 \\
\hline Host offers timely feedback and error-correction. & & 0.795 \\
\hline Perception of host interpretation-Interest & 0.91 & \\
\hline Host interpretation is interesting. & & 0.927 \\
\hline Host interpretation is fun. & & 0.903 \\
\hline Host interpretation is novel. & & 0.898 \\
\hline Perception of host interpretation-Matching degree with the festival & 0.81 & \\
\hline Host interpretation on waste sorting fits the festival program. & & 0.847 \\
\hline $\begin{array}{l}\text { Timing of host interpretation on waste sorting during the festival is } \\
\text { appropriate. }\end{array}$ & & 0.804 \\
\hline $\begin{array}{l}\text { Length of host interpretation on waste sorting during the festival is } \\
\text { appropriate. }\end{array}$ & & 0.826 \\
\hline $\begin{array}{c}\text { Host interpretation on waste sorting is consistent with host service in } \\
\text { general. }\end{array}$ & & 0.790 \\
\hline Perception of host interpretation-Collective learning & 0.79 & \\
\hline Host creates a sound collective learning atmosphere. & & 0.803 \\
\hline Host facilitates collective interactions. & & 0.787 \\
\hline Host encourages collective thinking. & & 0.791 \\
\hline Environmental attitude & 0.83 & \\
\hline Compulsory waste sorting is necessary for environmental protection. & & 0.855 \\
\hline Compulsory waste sorting is effective for environment protection. & & 0.829 \\
\hline Compulsory waste sorting is beneficial for environment protection. & & 0.818 \\
\hline Compulsory waste sorting is worth the inconveniences for me. & & 0.845 \\
\hline Behavioral intentions & 0.76 & \\
\hline $\begin{array}{l}\text { I will introduce waste sorting to family members and friends when } \\
\text { back home. }\end{array}$ & & 0.766 \\
\hline I will try waste sorting when back home. & & 0.749 \\
\hline \multirow{2}{*}{$\begin{array}{l}\text { I am willing to pay for equipment of waste sorting when back home. } \\
\text { I will get myself ready for compulsory waste sorting at my place of } \\
\text { residence. }\end{array}$} & & 0.780 \\
\hline & & 0.758 \\
\hline
\end{tabular}

Therefore, the reliability of the examined items for representing their respective dimensions could be established. The criteria of SEM, as specified by Byrne [39], designated measurement items with standardized factor loadings less than the value of 0.5 as insignificant and subject to the possibility of cross-loading and these should be discarded before further examinations. Accordingly, five dimensions carrying 20 items were identified as the scale of perception by festival attendees of the host's interpretation of compulsory waste sorting, with the refined measurements of festival attendees' learning outcomes, environmental attitudes and behavioral intentions accounted for by seven, four and four items, respectively.

The measurement model fit indices were reported at $\chi^{2}=684.745, d f=202, p<0.001$, Goodness of Fit $(\mathrm{GFI})=0.912$, Comparative Fit Index $(\mathrm{CFI})=0.907$, Root Mean Square Residue $(R M R)=0.070$, which, in accordance with the relevant criteria, conformed to a sound goodness of fit [40]. We concluded that the items of the refined scale were uniquely related to their respective proposed dimensions, with confirmation of their convergent validity.

The CFA process also tested the discriminant validity to ascertain the validation of the scale, through the analysis of the average variance extracted (AVE) $[40,45]$. The test results 
obtained a greater AVE for each of the proposed dimensions compared with the squared correlation coefficients of any two correlated dimensions, thereby establishing a tenable level of the discriminant validity of the proposed scale.

\subsection{SEM Results}

The SEM results of the external validity of the four-factor confirmatory model obtained a satisfactory level of goodness off it $\left(\chi^{2}=487.2529, d f=272, p<0.001\right.$, Normed Fit Index $(\mathrm{NFI})=0.90$, Comparative Fit Index $(\mathrm{CFI})=0.91$, Incremental Fit Index $(\mathrm{IFI})=0.93$ and Root Mean Square Error of Approximation (RMSEA) $=0.07$ ). A conclusion can be drawn that festival attendees' perceptions of the host interpretation, attendee learning outcomes and behavioral intentions concerning compulsory waste sorting were positively related to each other. Therefore, $\mathrm{H} 1$ and $\mathrm{H} 3$ were both supported.

To test $\mathrm{H} 2$ regarding the mediating role of the environmental attitudes between festival attendees' perceptions of the host interpretation and their learning outcomes, the Chi-square statistic for the structural model was reported at 63.43 , with the indication of a tenable model fit by all indices $\left(\chi^{2}=597.524, d f=272, p<0.001, \mathrm{CFI}=0.91, \mathrm{NFI}=0.93\right.$, $\mathrm{TLI}=0.91$ and RMSEA $=0.06$ ). This indicated that there was no direct effect of the festival attendees' perceptions of the host interpretation on their learning outcomes on compulsory waste sorting. However, the indirect effect of the perception of the host interpretation on learning outcomes through environmental attitudes was at the level of 0.18 , which was higher than the direct effect at 0.09 . This confirms the function of the environmental attitude as a full mediator on the relationship between the perception of the host interpretation and learning outcomes, thereby supporting H2 (Figure 2).

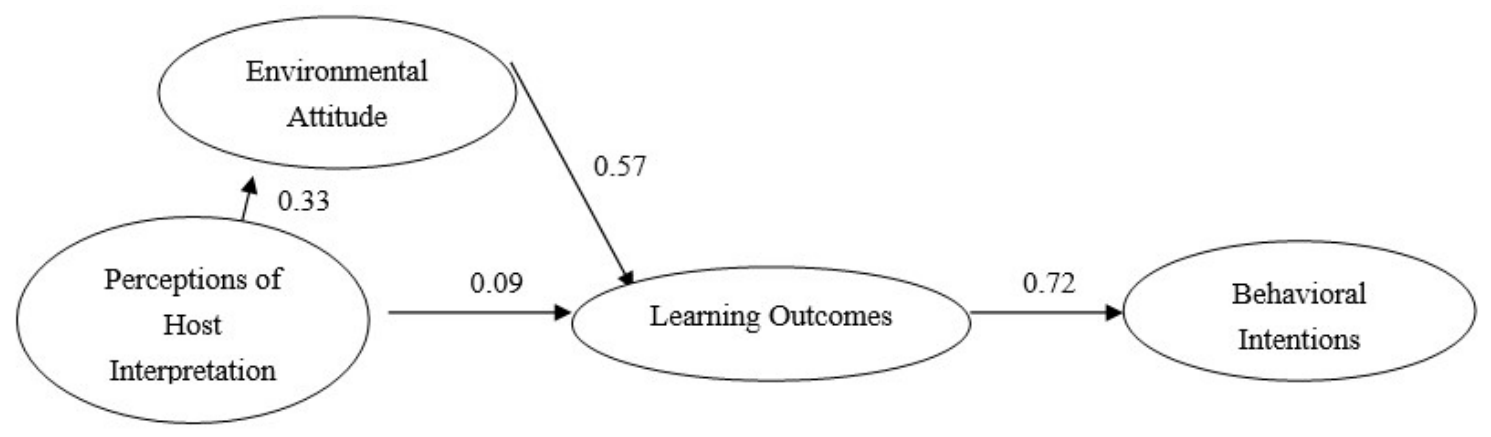

Figure 2. Structural equation models (SEMs) with parameter estimates.

Table 4 shows that the festival attendees' perceptions of host interpretation on compulsory waste sorting, being mediated by their attitude on the environment, exerted a positive effect on their learning outcomes $(\beta=0.25, t=5.237, p<0.001)$. The learning outcomes, in turn, affected behavioral intentions concerning compulsory waste sorting ( $\beta=0.72, t=6.018, p<0.001)$. Particularly, the tested scale could account for $63.3 \%$ and $65.5 \%$ of the variances in the learning outcomes and behavioral intentions, respectively. Thus, the festival attendees' perceptions of the host interpretation on compulsory waste sorting, mediated by their environmental attitude, were confirmed to be a reliable predictor of their learning outcomes and behavioral intentions. 
Table 4. The regression results.

\begin{tabular}{cccc}
\hline Hypothesized Path & Path Estimated & $t$-Value & Results \\
\hline $\begin{array}{c}\text { Perception of host interpretation } \\
\text { Learning outcomes }\end{array}$ & 0.090 & $0.414^{* * *}$ & Not supported \\
$\begin{array}{c}\text { Perception of host interpretation } \\
\text { Environmental attitude }\end{array}$ & 0.334 & $0.062^{* * *}$ & Supported \\
$\quad$ Environmental attitude & & & \\
$\quad$ Learning outcomes & 0.570 & $4.398^{* * *}$ & Supported \\
$\quad$ Learning outcomes & 0.725 & $0.048^{* * *}$ & Supported \\
$\quad$ Behavioral intentions & & & \\
$R^{2}$ (Learning outcomes) & 0.637 & & \\
$R^{2}$ (Behavioral intentions) & 0.662 & & \\
\hline Note: ${ }^{* * *} p<0.001$. & &
\end{tabular}

Lastly, multiple-regression analyses were conducted to explore the respective influences of the individual dimensions of the festival attendees' perceptions of the host interpretation on compulsory waste sorting on their learning outcomes as mediated by their environmental attitude. The regression results indicated an acceptable level of predictability for all five dimensions of the festival attendees perceptions of the host interpretation (at 0.001). The two most significant dimensions influencing the learning outcomes were the perception of knowledge and the perception of the matching degree with the festival, which, combined, contributed to $42.3 \%$ of the festival attendees' learning outcomes on compulsory waste sorting.

\section{Discussion}

This study explores and evaluates the learning processes of pro-environment knowledge and behavior in the semi-free choice learning context of festivals, an area that, despite its growing significance in the fabrics of contemporary economies and societies, has yet to be adequately addressed by current research efforts. The particular research issue of this study (compulsory waste sorting, which requires serious and in-depth understanding and reinforcement) provides a unique case on how guided festival attendance can facilitate the social normalization of public causes on sustainable development.

Employing a systematic modeling approach to comprehensively investigate the interrelationships among the significant factors identified, this study articulates the mechanism of such learning processes with the hierarchy of positive relationships between the host interpretation, learning outcomes and behavioral intentions of the festival attendees concerning compulsory waste sorting. The hypothesized positive paths between host interpretation and learning, learning outcomes and behavioral intentions were all confirmed. The objective measurement of the learning outcomes integrated by this study accentuates the effectiveness of the proposed structural model. The hypothesized path of the festival attendees' environmental attitude in mediating the learning outcomes was also confirmed. Festival host interpretation has functioned as an effective stimulus in arousing the responses of the festival attendees with regard to waste sorting, as facilitated by the organic environmental attitude already held by the attendees.

The findings of this study recognize the necessity and effectiveness of learning and practicing important local environmental regulations for festival attendees. For destinations that are dependent on festival or event-generated tourism, the volumes of annual festival attendees often rival the local population, and, during their stay, festival attendees, with their purchasing power and devoted motivations, tend to bring a greater environmental impact than the local residents in areas such as energy consumption, carbon emissions, and, inevitably, waste generation and disposal [7,9,32,35].

In this regard, local environmental regulations cannot be fully implemented without tenable and innovative mechanisms of communications with and compliance by these non-local demographic segments, for whom information and knowledge regarding environmental protection that is hard sold may not yield the expected effects. The examination 
and confirmation by this study of the effectiveness of host interpretation on the learning outcomes of festival attendees regarding compulsory waste sorting, therefore, consolidate an innovative path of realizing the mechanism of the cultivation of environmental knowledge and compliance.

\subsection{Theoretical Contribution and Practical Implications}

The results of this study also contribute to the theoretical understanding of the significant and distinctive functions of guided festival attendance in inducing and enhancing learning processes and outcomes of festival attendees with general travel purposes. The dimensions of the perceptions of host interpretations identified and confirmed by this study revealed how the host interpretation can help construct and leverage the experiential learning of festival or event visitors as stressed by previous research [9,14,27,30]. For visitors learning environmental and sustainability issues, proactive and targeted interpretation should not be missing. That said, host interpretation should not be simply equated with tutoring.

On one hand, host interpretations need to cater to the mindful learning of the festival attendees, who are sensitive to the authority of the interpretation by the host, opportunities of engagement with what they are experiencing, as well as a proper collective learning atmosphere. On the other hand, this study proved that the non-mindful aspects of festival experiences contribute to the learning outcomes of the attendees no less effectively than the mindful aspects. Stimulating and directing the non-mindful learning of the festival attendees, like the facets of arousing their interests and recognizing the consistency between the learning experiences and the experiences of the festival in general, can help complement and contextualize the mindful learning of festival attendees in a more amicable milieu and mitigate the potential intervening perceptions that may arise from mindful learning under free-choice scenarios.

Therefore, this study has empirically verified that the flow of learning is literally embedded in all aspects of festival attendance, especially for the learning of serious knowledge. Of course, to realize the integration of mindful and non-mindful learning of the festival participants, a higher sophistication of skills and attentiveness of the hosts is required, as well as meticulous planning and innovation of the festival product at both the managerial and destination levels [28].

By confirming the mediating role of the environmental attitude of the festival participants in influencing their learning outcomes from the perception of the host interpretation on compulsory waste sorting, this study pinpoints the significance of endogenous value stances in the festival attendees' internalization process of external information and knowledge input. The considerable influences of the environmental attitude may be explained by the transience of the festival experiences of the attendees during the festival when contrasted with their inherent attitudinal systems $[9,41]$.

The knowledge of the festival attendees of the ultimate national implementation of compulsory waste sorting in China may have reinforced their environmental attitudes toward this issue and consequently helped to shape their learning outcomes. Hence, to best deliver the host interpretation, equal emphasis should be placed upon the influencing environmental attitudes of the festival attendees, which cast subjective articulations on the external input and strongly determine their cognitive output. Particularly, for the learning outcomes of the festival attendees regarding compulsory waste sorting to maintain lasting impacts on their behaviors when back to their places of residence, their perceptions of the host interpretation need to be more closely synthesized and embodied with their environmental attitude both during the festival and for a sustained period of time after the festival.

Correspondingly, the findings of this study can serve as a valuable references for public and industrial practices in planning and formulating environmental education initiatives and programs on compulsory waste sorting or broader green and low carbon-related issues. The authorities of pilot destinations implementing compulsory waste sorting can integrate 
themed festivals and events into the cohort of educational and promotional campaigns on the issue and provide corresponding supplementary materials and training for festival and event hosts. A subsidy regimen for local festival operators and hosts that integrates interpretation on compulsory waste sorting into product packages would greatly motivate a greater degree of participation and devotion from the event and festival businesses and staff.

Cities in China that have yet to put compulsory waste sorting into practice can organize special trips for local environment protection officials and community representatives to the pilot cities to better learn about the practice and guide their own regulations. For industrial practitioners, more innovative strategies can be planned to improve the attractiveness of the educational components on compulsory waste sorting in the tour product portfolio. For instance, in view of the outstanding function of games in facilitating learning regarding environmental protection [42], various themed games could be developed and incorporated into festival planning and organization so as to arouse the interest of attendees and leverage their learning outcomes.

\subsection{Limitations and Future Research}

Future research can build upon the findings of this study and better capture the mechanisms of interpretation-guided visitor learning on environmental protection and sustainability issues. First, the structural model proposed and examined by this study can be enhanced and refined by future academic efforts, with improvements to the current variables and the incorporation of other important attributes congenial to visitor learning, such as environmental concern and environmental self-efficacy, as well as more tenable conceptualizations of festival attendee learning outcomes [7,17,32,34].

In addition, the generalizability of the results of this study may be limited due to restrictions of its sample of Chinese citizens attending a music-themed festival; therefore, cross-examinations with a more diversified sample base with varying socio-cultural backgrounds and festival-attending patterns would contribute to a more in-depth understanding of how waste sorting can be learned during festival attendance.

The application and examination of the measurement scales to festivals with other cultural or artistic themes in different countries would definitely help refine their validity and reliability. Last but not least, in light of the wide application of technology-assisted learning under various environmental education scenarios [47,48], understanding the effectiveness of visitor learning of compulsory waste sorting will be greatly leveraged by comparative analyses of the learning facilitated by host interpretations and by technology.

\section{Conclusions}

The findings of this study can serve as valuable references for public and industrial practices regarding compulsory waste sorting or broader green and low carbon-related issues. Our results confirm the hypothesized relationships and established positive learning outcomes for festival attendees on waste sorting as instructed by the festival hosts. The role of the festival attendees' environmental attitudes in mediating their learning outcomes has been highlighted. The examination and confirmation by this study of the effectiveness of host interpretation on the learning outcomes of festival attendees regarding compulsory waste sorting consolidate an innovative path of realizing the mechanism of the cultivation of environmental knowledge and compliance. Therefore, this study advances the understanding of the experiential learning processes of pro-environment and sustainability knowledge and behavior in festival contexts, areas that require future research as well as awareness of environmental protection and sustainable development. Industrial practitioners in both service and manufacturing sectors can refer to the findings of this study in formulating and implementing relevant customer-pivoted green strategies concerning waste sorting, with emphasis on customer learning and cultivation of their pro-green behaviors in free-choice contexts. Such strategies would not only improve the financial benchmarks of the enterprises but also manifest their corporate social responsibilities. 
Meanwhile, given the significance of the environmental attitude held by the researched individuals, a pro-green atmosphere needs to be cultivated among the general public through various educational and communications initiatives to boost the environmental awareness of all members of society with regard to waste sorting.

Author Contributions: Writing—original draft preparation, Q.Y.; writing—review and editing, H.J.S.; supervision, Q.Y.; project administration, Y.H.; funding acquisition, Q.Y. All authors have read and agreed to the published version of the manuscript.

Funding: The APC was funded by Nanjing Xiaozhuang University, China.

Conflicts of Interest: The authors declare no conflict of interest.

\section{References}

1. China Daily. The Era of Compulsory Garbage Sorting Begins. 2019. Available online: https://www.chinadaily.com.cn/a/201906 /24/WS5d10650ba3103dbf14329e23.html (accessed on 6 June 2020).

2. National Bureau of Statistics of China. 2019. Available online: http:/ / data.stats.gov.cn/easyquery.htm?cn=E0103 (accessed on 4 June 2020).

3. Yan, Q.; Ye, H.B. Why gold is so stronghold, revealing the mechanism of China's golden week holiday system. Leis. Stud. 2018, 37, 352-358.

4. Cecere, G.; Mancinelli, S.; Mazzanti, M. Waste prevention and social preferences: The role of intrinsic and extrinsic motivations. Ecol. Econ. 2014, 107, 163-176. [CrossRef]

5. Varotto, A.; Spagnolli, A. Psychological strategies to promote household recycling. A systematic review with meta-analysis of validated field interventions. J. Environ. Psychol. 2017, 51, 168-188. [CrossRef]

6. The South China Morning Post. 2019. Available online: https://www.scmp.com/news/china/society/article/3016801/shanghaibegins-new-waste-sorting-era-china-eyes-cleaner-image (accessed on 4 June 2020).

7. Zhang, Y.; Lee, T.J.; Xiong, Y. A conflict resolution model for sustainable heritage tourism. Int. J. Tour. Res. 2019, 21, 478-492. [CrossRef]

8. Rafiee, A.; Gordi, E.; Lu, W.; Miyata, Y.; Shabani, H.; Mortezazadeh, S.; Hoseini, M. The impact of various festivals and events on recycling potential of municipal solid waste in Tehran, Iran. J. Clean. Prod. 2018, 183, 77-86. [CrossRef]

9. Alonso-Vazquez, M.; Lee, T.J.; Tkaczynski, A. Key characteristics of green festivals: A critical review of the music and arts festival. In Proceedings of the 2nd International Tourism Conference: Tourism, Culture and the Creative Industries: Exploring the Linkages, St. Augustine, Trinidad and Tobago, 8-21 January 2012.

10. Steves, R. Travel as a Political Act; Nation Books: New York, NY, USA, 2009.

11. Henderson, S.; Musgrave, J. Changing audience behaviour: Festival goers and throwaway tents. Int. J. Event Festiv. Manag. 2014, 5, 247-262. [CrossRef]

12. Jaimangal-Jones, D.; Pritchard, A.; Morgan, N. Going the distance: Locating journey, liminality and rites of passage in dance music experiences. Leis. Stud. 2010, 29, 253-268. [CrossRef]

13. Webster, E.; McKay, G. From Glyndebourne to Glastonbury: The Impact of British Music Festivals. Norwich: Arts and Humanities Research Council/University of East Anglia. Available online: https://ueaeprints.uea.ac.uk/59132/1/Festival_Report_online. pdf.2016 (accessed on 6 June 2020).

14. Hitchings, R.; Browne, A.L.; Jack, T. Should there be more showers at the summer music festival? Studying the contextual dependence of resource consuming conventions and lessons for sustainable tourism. J. Sustain. Tour. 2018, 26, 496-514. [CrossRef]

15. Martinho, G.; Gomes, A.; Ramos, M.; Santos, P.; Gonçalves, G.; Fonseca, M.; Pires, A.; Martinho, G. Solid waste prevention and management at green festivals: A case study of the Andanças Festival, Portugal. Waste Manag. 2017, 71, 10-18. [CrossRef]

16. Chandrappa, R.; Das, D.B. Materials recovery and recycling. In Solid Waste Management; Springer: Berlin/Heidelberg, Germany, 2012; pp. 81-115.

17. Hottle, T.A.; Bilec, M.M.; Bown, N.R.; Landis, A.E. Toward zero waste: Composting and recycling for sustainable venue-based events. Waste Manag. 2015, 38, 86-94. [CrossRef]

18. Ballantyne, R.; Packer, J.; Sutherland, L.A. Visitors' memories of wildlife tourism: Implications for the design of powerful interpretive experiences. Tour. Manag. 2011, 32, 770-779. [CrossRef]

19. Crompton, J.L. Motivations for pleasure vacation. Ann. Tour. Res. 1979, 6, 408-424. [CrossRef]

20. Pearce, P.L.; Lee, U. Developing the travel career approach to tourist motivation. J. Travel Res. 2005, 43, 226-237. [CrossRef]

21. Yan, Q.; Hu, Y. work to leave, leave to work: Motivations of the Jobby moon takers: Evidence from focus group interviews. Leis. Stud. 2019, 38, 558-567. [CrossRef]

22. Stebbins, R. Serious leisure: A conceptual statement. Pacific Sociol. Rev. 1982, 25, $251-272$.

23. Luo, J.M.; Lam, C.F.; Ye, H. Barriers for the sustainable of entertainment tourism development in Macau. Sustainability 2019, 11, 1378. [CrossRef]

24. Su, L.; Swanson, S.R. The effect of martin destination social responsibility on tourist environmentally responsible behavior: Compared analysis of first-time and repeat tourists. Tour. Manag. 2017, 60, 308-321. [CrossRef] 
25. McIntosh, A.J. Into the tourist's mind: Understanding the value of the heritage experience. J. Travel Tour. Mark. 1999, 8, 41-64. [CrossRef]

26. Pirson, M.; Langer, E.J.; Bodner, T.; Zilcha-Mano, S. The Development and Validation of the Langer Mindfulness Scale-Enabling a Socio-Cognitive Perspective in Mindfulness in Organizational Contexts. 2012. Available online: http://ssrn.com/abstract=2158 921 (accessed on 18 June 2020).

27. Gartner, C. Enhancing readiness for change by enhancing mindfulness. J. Chang. Manag. 2013, 13, 52-68. [CrossRef]

28. Chan, J.K.L. The consumption of museum service experiences. J. Hosp. Mark. Manag. 2009, 18, 173-196.

29. Soren, B.J. Museum experiences that change visitors. Mus. Manag. Curatorship 2009, 24, 233-251. [CrossRef]

30. Packer, J. Beyond learning: Exploring visitors' perceptions of the value and benefits of museum experiences. Curator 2008, 51, 33-54. [CrossRef]

31. Luoh, H.F.; Sheng-HshiungTsaur, S.H.; Lo, P.C. Cooking for fun: The sources of fun in cooking learning tourism. J. Destin. Mark. Manag. 2020, 17, 1-8. [CrossRef]

32. Sirakaya-Turk, E.; Altintas, V. Evaluating communication competency of tour guides using a modified importance-performance analysis (MIPA). Int. J. Contemp. Hosp. Manag. 2016, 28, 195-218.

33. Huang, S.; Hsu, C.H.C.; Chan, A. Tour guide performance and tourist satisfaction: A study of the package tours in Shanghai. J. Hosp. Tour. Res. 2010, 34, 3-33. [CrossRef]

34. Randall, C.; Rollins, R.B. Visitor perceptions of the role of tour guides in natural areas. J. Sustain. Tour. 2009, 17, 357-374. [CrossRef]

35. Hines, J.M.; Hungerford, H.R.; Tomera, A.N. Analysis and synthesis of research on responsible environmental behavior: A meta-analysis. J. Environ. Educ. 1987, 18, 1-8. [CrossRef]

36. Sparks, B.; Pan, W. Chinese outbound tourists: Understanding their attitudes, constraints and use of information sources. Tour. Manag. 2008, 30, 483-494. [CrossRef]

37. Li, Q.C.; Wu, M.Y. Rationality or morality? A comparative study of pro-environmental intentions of local and nonlocal visitors in nature-based destinations. J. Destin. Mark. Manag. 2019, 11, 130-139. [CrossRef]

38. Dunlap, R.E. The new environmental paradigm scale: From marginality to worldwide use. J. Environ. Educ. 2008, 40, 3-18. [CrossRef]

39. Line, N.D.; Hanks, L. The effects of environmental and luxury beliefs on intention to patronize green hotels: The moderating effect of destination image. J. Sustain. Tour. 2016, 24, 904-925. [CrossRef]

40. Kaiser, F.G.; Wolfing, S.; Fuhrer, U. Environmental attitude and ecological behavior. J. Environ. Psychol. 1999, 19, 1-19. [CrossRef]

41. Kaiser, F.G.; Wilson, M. Goal-directed conservation behavior: The specific composition of a general performance. Personal. Individ. Differ. 2004, 36, 1531-1544. [CrossRef]

42. Lee, T.H.; Crompton, J. Measuring novelty seeking in tourism. Ann. Tour. Res. 1992, 19, 732-751. [CrossRef]

43. Anderson, J.C.; Gerbing, D.W. Structural equation modeling in practice: A review and recommended two-step approach. Psychol. Bull. 1988, 103, 411-423. [CrossRef]

44. Byrne, B.B. Principles and Practice of Structural Equation Modeling; Guilford Press: New York, NY, USA, 2010.

45. Hu, L.; Bentler, P.M. Fit indices in covariance structure modeling: Sensitivity to under parameterized model misspecification. Psychol. Methods 1998, 3, 424-453. [CrossRef]

46. Lee, T.H.; Jan, F.H.; Yang, C.C. Conceptualizing and measuring environmentally responsible behaviors from the perspective of community-based tourists. Tour. Manag. 2013, 36, 454-468. [CrossRef]

47. Menon, B.M.; Unnikrishnan, R.; Muir, A.; Rao, R.B. Serious game on recognizing categories of waste, to support a zero-waste recycling program. In Proceedings of the IEEE International Conference on Serious Games and Applications for Health, Perth, Australia, 2-4 April 2017.

48. Guo, S.; Ding, G.; Zhao, Q.; Jiang, M. Bonus point system for refuse classification and sustainable development: A study in China. Sustainability 2017, 9, 1776. [CrossRef] 